\title{
Circulating insulin inhibits glucagon secretion induced by arginine in type 1 diabetes
}

\author{
Per R Oskarsson ${ }^{1}$, Per-Eric Lins ${ }^{1}$, Bo Ahrén ${ }^{2}$ and Ulf C Adamson ${ }^{1}$ \\ ${ }^{1}$ Department of Medicine, Danderyd Hospital, Karolinska Institutet, Stockholm, Sweden and ${ }^{2}$ Department of Medicine, Lund University, Malmö, \\ Sweden
}

(Correspondence should be addressed to P Oskarsson, Department of Medicine, Danderyd Hospital, S-182 88 Danderyd, Sweden; Email: Per.Oskarsson@med.ds.sll.se)

\begin{abstract}
Objective: To evaluate if insulin has a suppressive effect on the glucagon secretion stimulated by arginine in type 1 diabetes.

Research design and methods: The alpha-cell response to an i.v. bolus of arginine $\left(150 \mathrm{mg} \mathrm{kg}^{-1}\right)$ followed by an infusion of arginine $\left(10 \mathrm{mg} \mathrm{kg}^{-1} \mathrm{~min}^{-1}\right)$ was studied in random order during either low dose infusion (LDT) or high dose infusion (HDT) of insulin in ten patients with type 1 diabetes. The blood glucose level was clamped at an arterialized level of $5 \mathrm{mmoll}^{-1}$ by a variable infusion of glucose. Venous C-peptide, glucagon, growth hormone, and insulin were analyzed.

Results: The mean plasma concentration of insulin was four times higher during the HDT. The C-peptide level did not differ between the LDT and the HDT. During the LDT in response to arginine the blood glucose level increased from 5.0 to $5.8 \mathrm{mmol} \mathrm{l}^{-1}$ although the glucose infusion was markedly reduced, while no change was seen during the HDT. A significantly smaller increase in the glucagon levels during the HDT was seen (area under the curve of $413 \pm 45$ vs $466 \pm 44 \mathrm{pg} \mathrm{ml}^{-1} \mathrm{~h}^{-1}, P=0.03$ ) while the growth hormone levels were almost identical.

Conclusion: This study demonstrates that a high level of circulating insulin exerts an inhibitory effect on the glucagon response to arginine in type 1 diabetes. Thus, the suppressive effect of insulin on the glucagon release from the alpha-cell seems to be general and not only dependent on stimulation by hypoglycemia.
\end{abstract}

European Journal of Endocrinology 142 30-34

\section{Introduction}

In patients with type 1 diabetes, the glucagon response to hypoglycemia is often sub-normal or absent (1) after a few years duration of the disease. This may be due to impairments in the autonomic stimulation of the alphacells, although a contribution of an impaired response to the lowering of blood glucose per se cannot be excluded (2). Furthermore, paracrine mechanisms due to the absent beta-cell function may also be of importance. In contrast, glucagon secretion induced by exercise (3) or an intravenous bolus of arginine seems to be unaltered in type 1 diabetes $(4,5)$.

Several factors are known to interfere in the secretory response of the alpha-cell, such as catecholamines (6, $7)$, the local glucose concentration $(8-10)$, the islet nerves (11) and the intra-islet insulin level (12).

Earlier experimental studies have shown that exogenous insulin inhibits basal glucagon secretion (13) and have also demonstrated that a high concentration of insulin may suppress the glucagon response to insulin-induced hypoglycemia in healthy subjects as well as in patients with type 1 diabetes (14-16).

This would suggest that the ambient circulatory level of insulin is of importance for glucagon secretion, which would be of clinical relevance in type 1 diabetes. However, the results showing that insulin inhibits hypoglycemia-induced glucagon secretion in type 1 diabetes do not prove that the direct secretion from the alpha-cells is sensitive to circulating insulin. The glucagon secretion induced by hypoglycemia in these patients is largely indirectly mediated by the autonomic nerves and catecholamines (2). For such a demonstration, it is necessary to examine the influence of insulin on glucagon secretion stimulated by an agent acting directly on the alpha-cells. Since this has never been demonstrated, we have, in the present study, investigated the possible suppressive effect of exogenously administered insulin on glucagon secretion after direct stimulation by arginine in type 1 diabetes. Arginine was used since it is a powerful stimulus in the activation of glucagon secretion and it exerts this effect by a direct 
effect on the glucagon producing alpha-cell. In order to achieve an inhibition of the potent stimuli of the alphacell by insulin probably through paracrine mechanisms, it was calculated that a high dose of insulin infusion would be needed. This study will provide data on the regulation by insulin of directly stimulated glucagon secretion in type 1 diabetes and will emphasize further the importance of keeping the insulin substitution levels as low as possible.

\section{Subjects and methods}

Ten patients with type 1 diabetes (two females), average age 37 (20-58) years, body mass index (BMI) $22.9 \pm$ $2.5 \mathrm{~kg} \mathrm{~m}^{-2}$, duration of disease $15(4-32)$ years, participated in the study. No patient had significant endogenous production of insulin as revealed from a negative $C$-peptide test. One patient had pre-proliferative and four had non-proliferative retinopathy; otherwise none had any signs of late diabetic complications. All patients were treated with four daily injections of insulin: short-acting insulin was given before breakfast, lunch and dinner, and intermediate-acting insulin was given at bedtime. No patient had a history of hypoglycemia unawareness. No episode of severe hypoglycemia was reported in the week preceding each experiment. Their glycated hemoglobin (HbAlc) was $6.9 \pm 0.5 \%$ (normal non-diabetic range $<5.2 \%$ ) in the low-dose experiment vs $7.0 \pm 0.5 \%$ in the high-dose experiment. The study protocol was approved by the local ethical committee and all patients gave their informed consent to participate in the study.

\section{Study protocol}

All patients' intermediate-acting insulin was withdrawn $36 \mathrm{~h}$ prior to the test. They were admitted to a metabolic ward the day before the test and were given short-acting insulin i.v. The rate of insulin infusion was adjusted on the basis of frequent blood glucose monitoring and was aimed at between 6 and $10 \mathrm{mmoll}^{-1}$. In the morning after an overnight fast, the patient came to the laboratory at $0730 \mathrm{~h}$ and was placed in a comfortable, semi-recumbent position for $30 \mathrm{~min}$ before the experiment. A short Teflon catheter was inserted into an antecubital vein on each side, one being used for infusions and the other for blood sampling for insulin, glucagon, growth hormone and C-peptide. A short teflon cannula was placed in a dorsal vein on the right hand which was placed in a warm-air box (Department of Medical Physics, Queens Medical Centre, Nottingham, Notts, UK), heated to $55-60{ }^{\circ} \mathrm{C}$ to arterialize the venous blood samples for analyses of blood glucose.

Each patient was studied on two occasions separated by at least two weeks. In random order, the patients were given insulin (Actrapid Human, Novo A/S, Copenhagen, Denmark) either as a low-dose infusion
(LDT) (244 pmol kg ${ }^{-1} \mathrm{~h}^{-1}$ ) or as a high-dose infusion (HDT) (1034 pmol kg ${ }^{-1} \mathrm{~h}^{-1}$ ). The blood glucose was clamped $30 \mathrm{~min}$ prior to the experiments and remained clamped during both experiments at a level of $5 \mathrm{mmoll}^{-1}$ by a variable intravenous infusion of glucose $(20 \%)$ adjusted at three-minute intervals. Ten milliliters human albumin solution $\left(20 \mathrm{mg} \mathrm{ml}^{-1}\right.$, Albumin, KabiVitrum, Stockholm, Sweden) were added to $490 \mathrm{ml}$ insulin-infusion solution in all experiments.

Following a steady state of blood glucose at a level of $5 \mathrm{mmol}^{-1}$ for $30 \mathrm{~min}$, an i.v. bolus of arginine hydrochloride $\left(150 \mathrm{mg} \mathrm{kg}^{-1}\right.$ ) was given, followed by an infusion of arginine hydrochloride $\left(10 \mathrm{mg} \mathrm{kg}^{-1}\right.$ $\mathrm{min}^{-1}$ ) for $30 \mathrm{~min}$. Arterialized blood samples for the analysis of blood glucose were obtained every third minute and venous blood samples for the analysis of plasma (p)-C-peptide, p-glucagon, p-growth hormone and p-free insulin were obtained at $-5,0,5,10,20$ and $30 \mathrm{~min}$. Blood pressure and pulse rate were recorded at the same intervals.

\section{Analyses}

Blood glucose was determined by a glucose analyzer (Yellow Springs Instruments, Yellow Springs, OH, USA). Plasma free insulin was determined according to Nakagawa et al. (17), using commercial radioimmunoassay kits (Pharmacia Diagnostics AB, Uppsala, Sweden) after precipitation of the antibody-bound insulin with $25 \%$ polyethylene glycol immediately following the blood collection. Plasma growth hormone was analyzed by radioimmunoassay (18). Plasma C-peptide and p-glucagon samples were obtained in prechilled test tubes containing aprotinin (250 kallikreininhibiting $\mathrm{U} \mathrm{ml}^{-1}$ blood; Bayer, Leverkusen, Germany). The tubes for p-glucagon also contained $0.084 \mathrm{ml}$ EDTA $\left(0.34 \mathrm{moll}^{-1}\right)$. C-peptide levels were measured with a radioimmunoassay technique using rabbit antiserum to synthetic human C-peptide (31 aminoacids). The immunogen was C-peptide N-terminally conjugated to bovine albumin (Euro-Diagnostica, Malmö, Sweden) (19). Glucagon levels were measured with a double-antibody radioimmunoassay in duplicate using guinea pig anti-human glucagon antibodies specific for pancreatic glucagon, ${ }^{125}$ I-glucagon as a tracer, and glucagon standard (Linco, St Charles, MO, USA) (20). The intra- and interassay coefficients of variation of determination were 3 and $7 \%$ respectively for glucagon.

\section{Statistical analyses}

Statistical significance was evaluated by means of a Student's two-tailed t-test for paired observations, a Wilcoxon signed rank test and analysis of variance (ANOVA) when applicable. $P$ values less than 0.05 were 

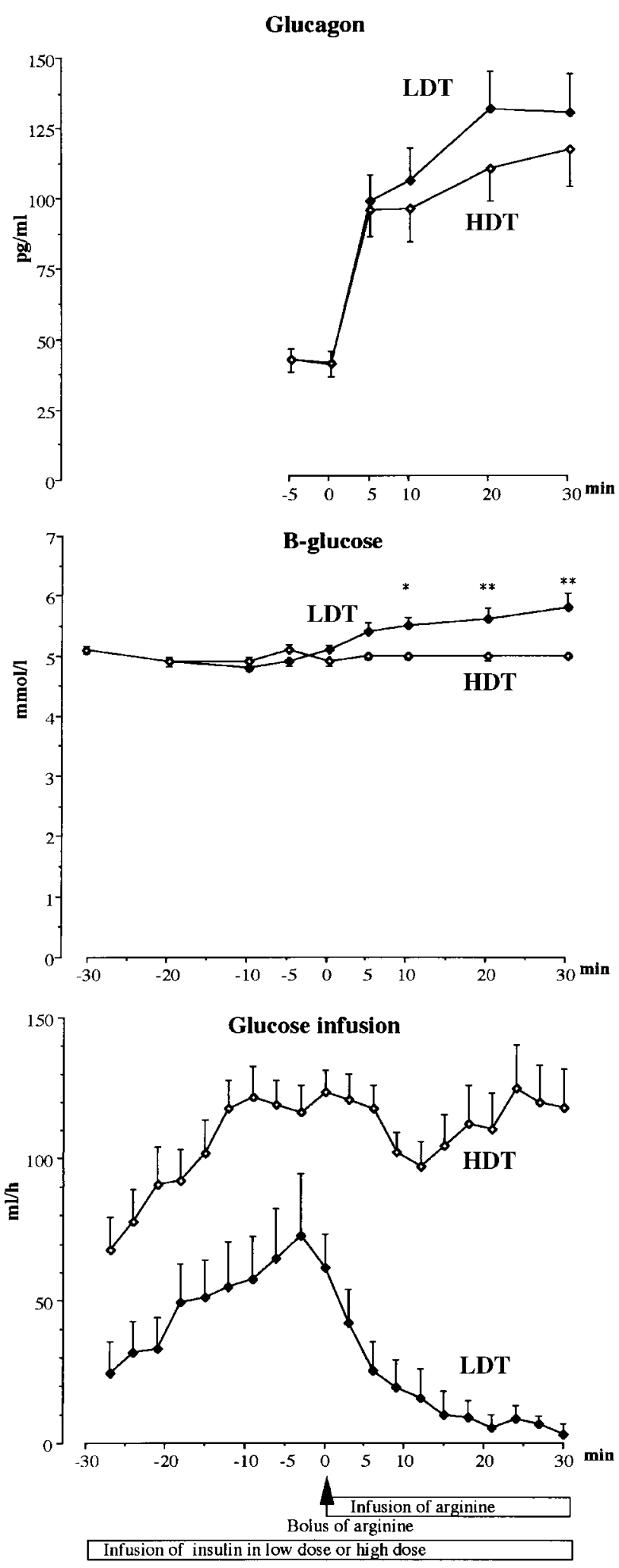

Figure 1 The values of p-glucagon, arterialized blood (B) glucose and glucose $(20 \%)$ infusion rate (means \pm S.E.) during LDT $(\bullet)$ and HDT $(\diamond)$ in 10 patients with type 1 diabetes. ${ }^{*} P<0.05$, ${ }^{* *} P<0.01$. considered significant. Unless otherwise stated, the data are given as means \pm S.E.M.

\section{Results}

The mean plasma free concentration of insulin during the LDT was $88 \pm 3$ pmoll $^{-1}$ compared with a four times higher concentration of $332 \pm 12 \mathrm{pmoll}^{-1}$ $(P<0.0001)$ during the HDT. The endogenous insulin secretion, as reflected by the $\mathrm{C}$-peptide level, was close to the detection limit in eight of the patients. There was no difference between LDT and HDT in C-peptide levels before $\left(0.16 \pm 0.03\right.$ vs $\left.0.16 \pm 0.03 \mathrm{nmoll}^{-1}\right)$ or after $\left(0.20 \pm 0.06\right.$ to $\left.0.19 \pm 0.04 \mathrm{nmoll}^{-1}\right)$ the arginine administration. Two patients had measurable concentrations and in these two the arginine challenge resulted in a slight increment of the C-peptide level $\left(0.21\right.$ and $\left.0.27 \mathrm{nmoll}^{-1}\right)$, but without any difference between the LDT and HDT.

The mean baseline concentrations of blood glucose were similar in the two tests. In the HDT, the glucose level remained close to the goal, i.e. $5 \mathrm{mmoll}^{-1}$, throughout the experiment. The same was true for the LDT for the period -30 to $0 \mathrm{~min}$. Thereafter, in the LDT the blood glucose rose to about 5.5 to $6 \mathrm{mmol}^{-1}$ (Fig. 1) in spite of the fact that the glucose infusion was markedly reduced and was even stopped in seven of the patients.

During the first $30 \mathrm{~min}$ of the clamp (i.e. -30 to $0 \mathrm{~min}$ ), there was a gradual and pronounced increase in the amount of the i.v. glucose infusion required to maintain euglycemia in both experiments, the difference being that during the HDT the amount infused was about two times higher. The i.v. arginine bolus and infusion had effects on exogenous glucose requirements in both the LDT and HDT as the expected continuous rise in glucose requirements was not seen after time 0 . However, the important difference between the tests was that this 'requirement' remained at a similar level in the HDT $(120 \mathrm{ml} / \mathrm{h})$ while a pronounced reduction was observed in the LDT (from 70 to $5 \mathrm{ml} / \mathrm{h}, P<0.009$ ). (Fig. 1). The total amount of glucose infused in the period 0 to 30 min was markedly lower in the LDT than in the HDT $(7.5 \pm 2.5$ vs $61.8 \pm 5.4 \mathrm{ml}, P<0.0001)$.

In response to arginine, the p-glucagon and p-growth hormone levels increased significantly in both experiments. The glucagon level had a similar initial prompt increase in both tests. However, after the initial peak, the glucagon level was lower in the HDT than in the LDT (Fig. 1). Also the mean area under the curves of p-glucagon (0-30 min) was significantly smaller in the HDT experiment compared with the LDT experiment (413 \pm 45 vs $466 \pm 44 \mathrm{pg} \mathrm{ml}^{-1} \mathrm{~h}^{-1}, P=0.03$; Fig. 2). In contrast, no significant difference in either the basal growth hormone level $(2.5 \pm 1.3$ vs $2.2 \pm 1.2)$ or the peak growth hormone level $(7.8 \pm 2.5$ vs $9.0 \pm$ $2.9 \mu \mathrm{gl}^{-1}$ ) was seen between the tests (Fig. 2).

There were no changes in the pulse rate or in blood pressure during either test (data not shown). 

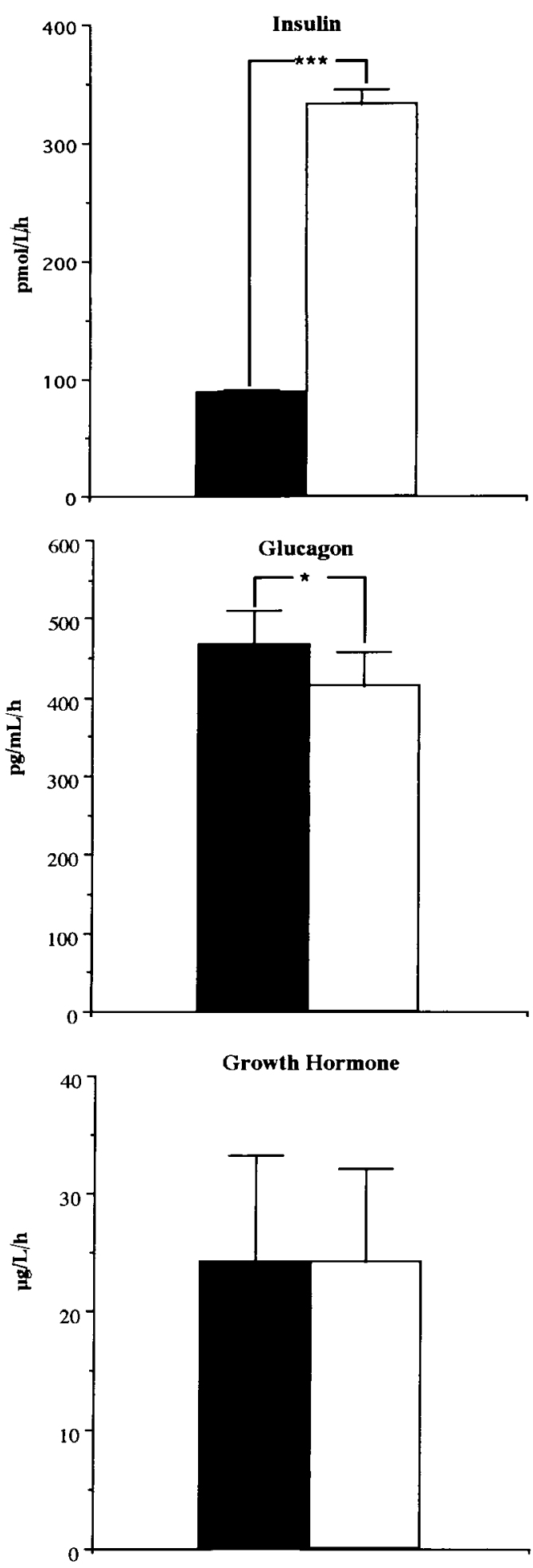

Figure 2 The mean area under the curve of plasma free insulin, plasma glucagon and plasma growth hormone ( \pm S.E.) during LDT (solid bars) and HDT (open bars) in 10 patients with type 1 diabetes. ${ }^{\star} P<0.05,{ }^{\star * \star} P<0.001$.

\section{Discussion}

This study shows that the glucagon response to i.v. arginine is reduced by a high level of circulating insulin in type 1 diabetes. Since arginine exerts its powerful glucagonotropic action through a direct effect on the glucagon-producing alpha-cells, the study provides evidence that insulin participates in the regulation of glucagon secretion in type 1 diabetes through a direct action on the alpha-cells. Previous studies on the effects of insulin on glucagon secretion in type 1 diabetes or in healthy subjects have only indirectly stimulated glucagon secretion, mainly through hypoglycemia (14-16) and our present study thus provides the first evidence that insulin exerts its glucagonostatic action in humans at the level of the alpha-cell in type 1 diabetes.

A difference in the glucose levels following the administration of the bolus of arginine was seen between the LDT and HDT experiments. Hyperglycemia has been shown to suppress glucagon levels and the glucagon response to arginine in normal man and in patients with type 2 diabetes (21-23). In contrast, an exaggerated response to arginine has been observed in patients with type 1 diabetes (24). However, this apparently paradoxical reaction is not attributed to hyperglycemia but to insulin deficiency $(24,25)$. Therefore, the modest difference in blood glucose (5.8 vs $5.0 \mathrm{mmol} / \mathrm{l}$ ) between the LDT and HDT cannot explain the difference in glucagon response.

Pharmacological stimulation of glucagon secretion by arginine is mediated through a direct action on the alpha-cells rather than indirectly through other hormones or the autonomic nervous system (26). Therefore, the most likely explanation for the inhibitory action of insulin on arginine-stimulated glucagon secretion in our study is a direct action of insulin on the alpha-cells. Such an action was previously demonstrated in experimental animals $(27,28)$ and our present study shows that this is also the case in type 1 diabetes patients.

It has previously been shown that even a minimal change in the glucagon levels could result in sustained hyperglycemia in a human deprived of insulin $(29,30)$. The changes in the glucagon levels seen in the LDT may seem small, but may be of functional importance since they resulted in a marked decrease in the need for supplementary i.v. glucose to maintain euglycemia. However, these experiments were relatively short and this must be kept in mind when interpreting the changes due to the glucose infusion rates.

This implies a need for an insulin substitution in type 1 diabetes in which the basal insulin levels are kept as low as possible.

In conclusion, this study demonstrates that a high level of circulating insulin exerts an inhibitory effect on the glucagon response to arginine in type 1 diabetes. Thus, the suppressive effect of insulin on the glucagon release from the alpha-cell seems to be general and not 
dependent on the stimuli. Furthermore, a marginal increase in the glucagon levels appears to exert significant effects on the glucose homeostasis in type 1 diabetes patients.

\section{Acknowledgements}

This work was supported by grants from the Bert von Kantzow Foundation, the Karolinska Institute and the Swedish Medical Research Council (grant nos 19x-6589 and 14x-6834).

\section{References}

1 Bolli G, de Feo P, Compagnucci P, Cartechini MG, Angeletti G, Santeusanio F, Brunetti P \& Gerich JE. Abnormal glucose counterregulation in insulin-dependent diabetes mellitus. Interaction of anti-insulin antibodies and impaired glucagon and epinephrine secretion. Diabetes 198332 134-141.

2 Taborsky GJ Jr, Ahren B \& Havel PJ. Autonomic mediation of glucagon secretion during hypoglycemia: implications for impaired alpha-cell responses in type 1 diabetes. Diabetes 1998 47 995-1005.

3 Tuttle K, Marker J, Dalsky G, Schwartz N, Shah S, Clutter W, Holloszy J \& Cryer P. Glucagon, not insulin, may play a secondary role in defense against hypoglycemia during exercise. American Journal of Physiology 1988254 E713-E719.

4 Gerich JE, Lorenzi M, Tsalikian E, Bohannon NV, Schneider V, Karam JH \& Forsham PH. Effects of acute insulin withdrawal and administration on plasma glucagon response to intravenous arginine in insulin-dependent diabetic subjects. Diabetes 197625 955-960.

5 Raskin P, Aydin I \& Unger RH. Effect of insulin on the exaggerated glucagon response to arginine stimulation in diabetes mellitus. Diabetes $197625227-229$.

6 Gerich JE, Karam JH \& Forsham PH. Stimulation of glucagon secretion by epinephrine in man. Journal of Clinical Endocrinology and Metabolism 197337 479-481.

7 Schuit FC \& Pipeleers DG. Differences in adrenergic recognition by pancreatic A and B cells. Science 1986232 875-877.

8 Gerich JE, Charles MA \& Grodsky GM. Characterization of the effects of arginine and glucose on glucagon and insulin release from the perfused rat pancreas. Journal of Clinical Investigation $197454833-841$.

9 Gerich JE, Langlois M, Noacco C, Lorenzi M, Karam JH \& Korsham PH. Comparison of the suppressive effects of elevated plasma glucose and free fatty acid levels on glucagon secretion in normal and insulin-dependent diabetic subjects. Evidence for selective alpha-cell insensitivity to glucose in diabetes mellitus. Journal of Clinical Investigation 197658 320-325.

10 Starke A, Grundy S, McGarry ID \& Unger RH. Correction of hyperglycemia with phloridzin restores the glucagon response to glucose in insulin-deficient dogs: implications for human diabetes. Proceedings of the National Academy of Sciences of the USA 198582 1544-1546.

11 Havel PJ \& Ahren B. Activation of autonomic nerves and the adrenal medulla contributes to increased glucagon secretion during moderate insulin-induced hypoglycemia in women. Diabetes $199746801-807$.

12 Peacey SR, Rostami-Hodjegan A, George E, Tucker GT \& HellerSR. The use of tolbutamide-induced hypoglycemia to examine the intraislet role of insulin in mediating glucagon release in normal humans. Journal of Clinical Endocrinology and Metabolism 199782 $1458-1461$.
13 Raskin P, Fujita Y \& Unger RH. Effect of insulin-glucose infusions on plasma glucagon levels in fasting diabetics and nondiabetics. Journal of Clinical Investigation 197556 1132-1138.

14 Diamond MP, Hallarman L, Starick ZK, Jones TW, Connolly HM, Tamborlane WV \& Sherwin RS. Suppression of counterregulatory hormone response to hypoglycemia by insulin per se. Journal of Clinical Endocrinology and Metabolism 199172 1388-1390.

15 Liu D, Moberg E, Kollind M, Lins PE \& Adamson U. A high concentration of circulating insulin suppresses the glucagon response to hypoglycemia in normal man. Journal of Clinical Endocrinology and Metabolism 199173 1123-1128.

16 Liu DT, Adamson UC, Lins PE, Kollind ME, Moberg EA \& Andreasson K. Inhibitory effect of circulating insulin on glucagon secretion during hypoglycemia in type I diabetic patients. Diabetes Care 199215 59-65.

17 Nakagawa S, Nakayama H, Sasaki T, Yoshino K \& Yu YY. A simple method for the determination of serum free insulin levels in insulin-treated patients. Diabetes 197322 590-600.

18 Cerasi E, Della Casa L, Luft R \& Roovete A. Determination of human growth hormone $(\mathrm{HGH})$ in plasma by a double antibody radioimmunoassay. Acta Endocrinologica $1966 \quad 53$ 101-120.

19 Heding L. Radioimmunological determination of human C-peptide in serum. Diabetologia $197511541-548$.

20 Ahren B \& Larsson H. Leptin - a regulator of islet function?: its plasma levels correlate with glucagon and insulin secretion in healthy women. Metabolism 199746 1477-1481.

21 Yamamoto T, Raskin P, Aydin I \& Unger R. Effects of insulin on the response of immunoreactive glucagon to an intravenous glucose load in human diabetes. Metabolism 197928 568-574.

22 Beard JC, Weinberg C, Pfeifer MA, Best JD, Halter JB \& Porte D Jr. Modulation of arginine-induced glucagon release by epinephrine and glucose levels in man. Journal of Clinical Endocrinology and Metabolism 198356 1271-1277.

23 Hollander PM, Asplin CM \& Palmer JP. Glucose modulation of insulin and glucagon secretion in nondiabetic and diabetic man. Diabetes $198231489-495$.

24 Kawamori R, Shichiri M, Kikuchi M, Yamasaki Y \& Abe H. The mechanism of exaggerated glucagon response to arginine in diabetes mellitus. Diabetes Research and Clinical Practice 19851 131-137.

25 McCulloch DK, Raghu PK, Koerker DJ, Palmer JP \& Klaff LJ. Responses of the pancreatic A cell during hypoglycemia and hyperglycemia are dependent on the B cell. Metabolism 198938 702-707.

26 Pipeleers DG, Schuit FC, Van Schravendijk CF \& Van de Winkel M. Interplay of nutrients and hormones in the regulation of glucagon release. Endocrinology $1985117817-$ 823.

27 Maruyama H, Hisatomi A, Orci L, Grodsky GM \& Unger RH. Insulin within islets is a physiologic glucagon release inhibitor. Journal of Clinical Investigation 198474 2296-2299.

28 Unger RH. The Berson memorial lecture. Insulin-glucagon relationships in the defense against hypoglycemia. Diabetes $198332575-583$.

29 Lins PE, Wajngot A, Adamson U, Vranic M \& Efendic S. Minimal increases in glucagon levels enhance glucose production in man with partial hypoinsulinemia. Diabetes 198332 633636.

30 Barnes AJ, Bloom SR, George K, Alberti KG, Smythe P, Alford FP \& Chisholm DJ. Ketoacidosis in pancreatectomized man. New England Journal of Medicine 1977296 1250-1253.

Received 7 April 1999

Accepted 20 August 1999 